\title{
CARACTERIZACIÓN AGRONÓMICA, CALIDAD INDUSTRIAL Y NUTRICIONAL DE MAÍZ PARA EL TRÓPICO MEXICANO ${ }^{1}$
}

\author{
Mauro Sierra-Macías ${ }^{2}$, Artemio Palafox-Caballero ${ }^{2}$, Gricelda Vázquez-Carrillo ${ }^{3}$,Flavio Rodríguez-Montalvo ${ }^{2}$, \\ Alejandro Espinosa-Calderón ${ }^{3}$
}

\section{RESUMEN}

Caracterización agronómica, calidad industrial y nutricional de maíz para el trópico mexicano. El objetivo de este trabajo fue determinar el valor agronómico y nutricional de variedades e híbridos de maíz en Veracruz, México, durante el ciclo primavera verano 2006. Se validaron híbridos y variedades de maíz normal y con alta calidad de proteína en Cotaxtla, Mata de Agua, Tlalixcoyan, Ignacio de la Llave, Martínez de la Torre y Rodríguez Clara, en Veracruz, México. Se utilizó un diseño de bloques completos al azar con dos repeticiones y parcelas de ocho surcos de $25 \mathrm{~m}$ de largo con una densidad de 62500 semillas/ha. Del análisis de varianza combinado, se encontró diferencia altamente significativa para Genotipos (G), Localidades (L) y la interacción GxL. Los genotipos sobresalientes, por su rendimiento de grano y otras características agronómicas fueron HQ4, H-520, HQ3 y HQ1 con 5,42; 5,38; 5,13 y 5,06 t/ha, respectivamente. Los híbridos con mejor valor nutricional de grano blanco fueron HQ1, HQ3 y HQ4, y la variedad V-556AC, de grano amarillo, calidad basada en características físicas, químicas, de nixtamal, la masa y las tortillas, así como los aminoácidos lisina y triptofano, en endospermo, grano entero y tortillas. Estos maíces cumplen con las especificaciones de la norma mexicana para maíces destinados al proceso de nixtamalización. El HQ1 produjo las mejores tortillas, y el híbrido HQ4, se consideró apropiado para la industria de la harina nixtamalizada.

Palabras clave: Zea mays, híbridos, calidad nutritiva, nixtamalización, industrialización.

\begin{abstract}
Agronomic characterization, industrial and nutritional quality of maize for the Mexican tropics. The objective of this work was to determine the agronomic and nutritional value of maize varieties and hybrids in Veracruz, México, during the spring-summer cycle of year 2006. Normal and high-protein content hybrids and varieties were validated in Cotaxtla, Mata de Agua, Tlalixcoyan, Ignacio de la Llave, Martínez de la Torre y Rodríguez Clara, in Veracruz, México. A randomized complete block design with two replications was employed, with plots composed of eight $25 \mathrm{~m}$-long rows and a density of 62500 seeds/ha. The combined analysis of variance showed highly significant differences for Genotypes $(\mathrm{G})$, Locations (L), and for the interaction $G \times \mathrm{L}$. The outstanding genotypes for grain yield and other agronomic characteristics were: HQ4, H-520, HQ3 and HQ1, with 5.42, $5.38,5.13$ and $5.06 \mathrm{Mg} / \mathrm{ha}$, respectively, all of which showed good plant and ear appearance. The genotypes with higher nutritional value were the white hybrids HQ1, HQ3 and HQ4 and the yellow corn variety V-556AC. Quality was assessed according to chemical and physical features, nixtamalization, dough and tortilla processing, and tryptophan and lysine content. These genotypes complied with the Mexican specifications for corn destined to nixtamalization. The Q1 produced the best tortillas, and the hybrid HQ4 was considered appropriate for the industry of nixtamal flour process.
\end{abstract}

Key words: Zea mays, hybrids, nutritive quality, nixtamalization, industrialization.

\footnotetext{
1 Recibido: 23 de marzo, 2009. Aceptado: 21 de mayo, 2010. Este trabajo deriva de los proyectos: "Combatiendo el hambre oculta en América Latina, cultivos biofortificados con vitamina, minerales esenciales y proteína de calidad mejorados" CIMMYT, CIDA Canadá, y "Mejoramiento de la calidad nutritiva e industrial del maíz" del INIFAP, México.

2 Investigadores de la red de maíz. Campo Experimental Cotaxtla, Instituto Nacional de Investigaciones, Forestales Agrícolas y Pecuarias (INIFAP). km 34 Carr. Veracruz - Córdoba. Apdo. postal 429, Veracruz, Ver., 91700, México. sierra.mauro@inifap.gob.mx, mauro_s55@ hotmail.com; palafox.artemio@inifap.gob.mx; rodriguez.flavio@inifap.gob.mx; rodriguez.jose@inifap.gob.mx

3 Campo Experimental Valle de México. Instituto Nacional de Investigaciones Forestales, Agrícolas y Pecuarias (INIFAP). Texcoco, México. espinosa.alejandro@inifap.gob.mx; vasquez.gricelda@inifap.gob.mx
} 


\section{INTRODUCCIÓN}

En México, el cultivo de maíz (Zea mays L.) es el más importante por su superficie sembrada, valor de la producción, por ser el alimento principal de la población y por ocupar el 20 por ciento de la población económicamente activa. En 2002 se sembraron en México 6,48 millones de ha con este cultivo, con un rendimiento de 2,32 t/ha (SAGARPA 2002). En el área tropical se siembran 2,5 millones de hectáreas, de las cuales un millón están comprendidas en provincias agronómicas de buena y muy buena productividad y donde es factible el uso de semilla mejorada de híbridos y variedades sintéticas (Sierra et al. 2001 y Sierra et al. 2004)

En México existen 31 millones de personas con desnutrición, de los cuales 18 millones la padecen en forma severa (Espinosa et al. 2006), se trata de diez millones de indígenas y el resto es población urbana de bajos ingresos. De éstos, el 50\% corresponden a niños menores de cinco años de las áreas rurales y el 30\% de las urbanas (Espinosa et al. 2006, Chávez y Chávez 2004). En este marco, el maíz es fundamental en la alimentación de los mexicanos, ya que se calcula un consumo per cápita aparente de 209,8 kilogramos (Morris y López 2000). En México se consumen 12,3 millones de toneladas de maíz en forma de tortilla, de los cuales el $64 \%$ es a través del método tradicional maíz-masa-tortilla y el $36 \%$ es a través de la industria de la harinización (SAGARPA 2008).

El maíz con alta calidad de proteína deriva del aprovechamiento del gene mutante opaco 0202 . Su versión homocigótica recesiva genera mayor contenido de lisina y triptófano, aminoácidos componentes de las proteínas esenciales para el crecimiento y desarrollo humano (Mertz 1994, Ortega et al. 1986, Vasal 2002). La calidad de la proteína en estos maíces es similar a la de la leche (Bressani 1994). Vasal et al. (1994) concentraron genes modificadores del endospermo, para lograr la textura cristalina o dentada en el grano, que expresa el gene $\mathrm{o} 2 \mathrm{o} 2$, obteniendo con ello líneas, híbridos y variedades con la textura del maíz común, con características aptas para la industria, para el método de consumo tradicional.

Mediante técnicas de mejoramiento tradicionales, Vasal y Villegas (2001) incorporaron una serie de genes especiales al maíz opaco o2o2, llamados genes modificadores de la textura del endospermo, por lo que en la década de los 80 s, se obtuvo el maíz con alta calidad de proteína. Estos genes modificadores confieren al endospermo de las variedades, líneas e híbridos, una textura de grano más dura que el maíz opaco, dando la apariencia del maíz común o normal. Larkins et al. (1994), indicaron que los maíces con el gene o2o2, contienen de 40 a 50\% más lisina y de 35 a $40 \%$ más triptófano.

El valor nutritivo de los componentes del endospermo y del embrión del grano de maíz puede variar según el tipo y la variedad, por efecto del ambiente y del manejo agronómico; sin embargo, en los maíces tropicales H-519C, H-553C y V-537C, se encontró que el contenido de triptófano se incrementó en 59, 44 y $74 \%$, mientras que el contenido de lisina se incrementó en 50, 46 y $47 \%$ para cada genotipo respectivamente, (Sierra et al. 2001). Resultados similares fueron encontrados por Ortega et al. (2001) para los híbridos $\mathrm{H}-441 \mathrm{C}, \mathrm{H}-442 \mathrm{C}$ y $\mathrm{H}-469 \mathrm{C}$ recomendados para el Noroeste y regiones subtropicales de México.

Como atributos de una tortilla de buena calidad puede considerarse los siguientes: fácil enrollado, suavidad al tacto, olor, sabor, textura y plasticidad; tales atributos se obtienen mediante un procesamiento con concentraciones adecuadas de cal y tiempos apropiados de cocimiento (Antuna et al. 2008). Por su parte, Arámbula et al. (2001), mencionan que para la elaboración de tortillas se requiere un grano que produzca masa con alta humedad, buena extensibilidad y resistencia entre otras características.

En un estudio sobre calidad de grano, tortillas y botanas en las variedades de maíz de la raza comiteco V-229 y V-231A, Coutiño et al. (2008) encontraron que estas variedades son aptas para la industria tradicional de la masa y la tortilla; los procesos de nixtamalización y de elaboración de éstas no redujeron los contenidos de lisina encontrados en el grano; en cambio, en triptófano hubo pérdidas de $57 \%$ en la variedad V-229 y de $43 \%$ en la V-231A.

Estudios preliminares (Sierra et al. 2007), permitieron identificar los genotipos HQ1, HQ2, HQ3 y HQ4, híbridos de maíz con características agronómicas deseables, principalmente rendimiento y tolerancia a la enfermedad del "achaparramiento", y propiedades adecuadas para la industria de masa- tortilla.

El objetivo de este trabajo fue determinar el valor agronómico y nutricional de variedades e híbridos de maíz en Veracruz, México. 


\section{MATERIALES Y MÉTODOS}

Localización. Durante el ciclo primavera verano 2006, en el estado de Veracruz, México, se establecieron parcelas de validación de maíz normal y con alta calidad de proteína en seis localidades: Cotaxtla municipio de Medellín de Bravo, La Torrecilla, Municipio de Tlalixcoyan, Zapotal Número Uno, municipio de Ignacio de la Llave, Mata de Agua municipio de Adalberto Tejeda, Ejido Graciano Sánchez, municipio de Martínez de la Torre y CBTA 85, municipio de Rodríguez Clara. La clasificación climática de Köppen modificada fue Aw1, Aw2, Aw2, Aw0, Am y Aw1, para cada localidad, climas cálido húmedo y subhúmedo, respectivamente (García 1981). Los análisis de calidad industrial y nutricional se efectuaron en el laboratorio de maíz del Instituto Nacional de Investigaciones Forestales, Agrícolas y Pecuarias (INIFAP) en el Campo Experimental Valle de México.

En cuanto al tipo de suelo, la localidad de Cotaxtla es de tipo Franco, las localidades de Tallixcoyan e Ignacio de la Llave, son del tipo Franco Arcilloso, Mata de Agua y Rodríguez Clara son migajón arenoso y Martínez de la Torre es migajón arcilloso. En cuanto al pH, Rodríguez Clara registra el pH más bajo $(4,6)$, Martínez de la Torre es ligeramente alcalino $(7,3)$ y el resto de las localidades son de tendencia al neutro.

Germoplasma utilizado. Se evaluaron cuatro híbridos experimentales de maíz con alta calidad de proteína HQ1, HQ2, HQ3, HQ4, dos híbridos trilineales normales H-518 y H-520, dos variedades de maíz con alta calidad de proteína V-537C y V-556AC, la variedad sintética normal VS-536 y el híbrido comercial A 7573.

Descripción de los lotes de validación. Los lotes fueron establecidos bajo diseño de bloques al azar con 10 tratamientos y dos repeticiones. Parcelas de 10 surcos de $25 \mathrm{~m}$ de largo separados a $80 \mathrm{~cm}$ con dos semillas cada $40 \mathrm{~cm}$ para una densidad de 62 500 semillas/ha. El control de las malezas se efectuó con Atrazina en dosis de $3 \mathrm{~kg} / \mathrm{ha}$. Se fertilizó con la fórmula 161-46-00 donde se aplicó $100 \mathrm{~kg}$ de urea más $100 \mathrm{~kg}$ de Super Fosfato de Calcio Triple (SPCT) durante los primeros 10 días a partir de la siembra y el resto del nitrógeno al momento del atierre.

Variables y registro de datos. Las variables fueron: Rendimiento de grano, la altura de planta y de mazorca, medidas en $\mathrm{cm}$ desde el suelo hasta la altura de la hoja bandera y hasta el nudo donde se inserta la mazorca principal; los días a floración masculina y femenina, se obtuvieron a partir de la fecha de siembra y el momento donde se tienen el $50 \%$ de las espigas soltando polen y $50 \%$ de los estigmas receptivos; calificaciones de aspecto y sanidad de planta y de mazorca con escala de uno a cinco donde, uno se refiere a plantas vigorosas, sanas, con buena carga en mazorca, sin acame, o bien, mazorcas grandes, sin daño en pudrición, uniformes, de hileras regulares y cinco corresponde a las plantas con poco vigor, dañadas por enfermedades y mazorcas pequeñas, y con el mayor daño por pudrición, porcentaje de plantas acamadas, porcentaje de mazorcas con mala cobertura, y porcentaje de mazorcas podridas.

Calidad industrial y nutricional. Se evaluaron tres híbridos de grano blanco: HQ-1, HQ-3 y HQ-4, y la variedad de grano amarillo V-556AC, genotipos de maíz con alta calidad de proteína (ACP), en los que se determinaron características físicas, químicas, del nixtamal, la masa y las tortillas, así como los aminoácidos lisina y triptofano, en endospermo, grano entero y tortillas, siguiendo las metodologías de la American Association of Cereal Chemists AACC (1998), Association of Official Analytical Chemists AOAC (1984), las descritas en la Norma Mexicana para Maíces Destinados al Proceso de Nixtamalización, NMX-034(1) (2002) y las declaradas por Salinas y Vázquez (2006).

Calidad de la harina nixtamalizada. Se identificaron los maíces cuyo índice de flotación fue menor o igual a $20 \%$, color del grano con valores de reflectancia superiores al 55\% en el equipo Agtron. Posteriormente se evaluó el color en harinas de grano sin procesar, cuyos valores deben ser iguales o mayores al $77 \%$.

El color se midió en grano entero y en tortilla, usando el colorímetro Mini Scan XE plus (Hunter Lab, modelo 45/0-L), que descompone el color en tres variables: $L^{*}$ que representa la luminosidad y cuyos valores van del 100, que corresponde al blanco, hasta cero para el negro; la escala $a^{*}$ que registra valores positivos cuando están presentes los tonos rojos y adquiere valores negativos cuando registra tonos verdes. La variable $b^{*}$ Califica los colores amarillos $(+)$ a azul (-). Con las variables $a^{*} \mathrm{y} \mathrm{b}^{*}$ se calculó el ángulo del tono hue o tinte (hue $=\arctan \mathrm{a} / \mathrm{b}$ ), que es un valor angular, el cual indica el cuadrante correspondiente al color de la muestra en un sistema cartesiano, donde el eje $\mathrm{X}$ correspopnde a los valores de a y el eje $\mathrm{Y}$ a los de $\mathrm{b}$, donde $0^{\circ}=$ color rojo-púrpura; $90^{\circ}=$ amarillo; $180^{\circ}=$ verde; $y 270^{\circ}=$ azul (Mc Guire 1992). 
La evaluación final consistió en cuantificar el porcentaje de endospermo córneo, el cual debe ser igual o superior al $48 \%$. Se evaluaron dos muestras por repetición; por lo tanto, los valores que se presentan sobre el grano, nixtamal, tortilla y harina, son el promedio de cuatro determinaciones.

Métodos estadísticos. Se hicieron análisis de varianza individuales para las variables en estudio y análisis combinado para rendimiento de grano, altura de planta y de mazorca, días a floración masculina y femenina, aspecto y sanidad de planta y de mazorca. Los datos registrados en porcentaje fueron transformados a grados angulares (bliss), para proceder al análisis de varianza. La separación de medias se hizo mediante la prueba Diferencia Mínima Significativa (DMS) (Reyes 1990).

Los índices ambientales hacen referencia a la diferencia del rendimiento medio por localidad y el promedio de rendimiento a través de los seis ambientes.

\section{RESULTADOS Y DISCUSIÓN}

Se encontró diferencia altamente significativa para genotipos $(\mathrm{G})$, localidades (L) y para la interacción GxL, en las variables: rendimiento de grano, días a floración masculina y femenina, aspecto y sanidad de planta. Lo anterior sugiere que el comportamiento de los genotipos en relación con estas variables es diferente en las localidades evaluadas. No hubo significancia estadística para la interacción GxL en las variables aspecto y sanidad de mazorca y altura de planta y de mazorca. Una mayor varianza debida al factor localidades, se dio en las variables rendimiento de grano, altura de planta y de mazorca, lo que indica que dichas localidades fueron diferentes en cuanto a clima, suelo y manejo por parte de los agricultores. Los coeficientes de variación para las variables evaluadas fueron relativamente bajos $(12,68 ; 5,81 ; 12,12$; 1,$82 ; 1,92 ; 13,51 ; 15,01 ; 18,61$ y $18,61 \%$ para cada variable respectivamente), valores que sugieren que la conducción de los lotes y los resultados obtenidos son confiables (Reyes 1990).

\section{Rendimiento de grano}

Por lo que se refiere al rendimiento de grano de los genotipos de maíz normal y con alta calidad de proteína (Cuadro 1), se encontró un grupo de cuatro híbridos significativamente superiores a través de las seis localidades de evaluación al 0,05 de probabilidad. Los híbridos son: HQ4, H-520, HQ3, y HQ1, con rendimientos de 5,$42 ; 5,38 ; 5,13$ y 5,06 t/ha; superiores de un 13 a $21 \%$ en relación al testigo comercial. De éstos, tres son genotipos con alta calidad de proteína y H-520 es un híbrido normal.

La localidad de Cotaxtla registró un rendimiento significativamente más alto $(7,01 \mathrm{t} / \mathrm{ha})$, con un índice ambiental positivo de 2,28. Por el contrario, las localidades de Rodríguez Clara en el sur de Veracruz y Graciano Sánchez en Martínez de la Torre, registraron los rendimientos más bajos $(2,74$ y 3,91 t/ha) e índices ambientales negativos de $-1,99$ y $-0,82$ para cada localidad respectivamente (Cuadro 2). Esto debido seguramente al tipo de suelo migajón arenoso y al pH ácido $(4,6)$ en el caso de la localidad de Rodríguez Clara y el suelo migajón arcilloso en la localidad de Graciano Sánchez en Martínez de la Torre, Ver.

\section{Características agronómicas}

Con relación a las características agronómicas (Cuadro 3), los genotipos en validación registraron una altura de planta y una altura de mazorca intermedia baja y un ciclo biológico intermedio. Las mejores calificaciones de aspecto y sanidad en planta fueron para los híbridos HQ1, HQ4 y H-520, con bajos porcentajes de mazorcas podridas.

Finalmente, las mejores calificaciones de aspecto y sanidad en mazorca se registraron para los genotipos HQ4 y H-520. Estos dos híbridos también tuvieron bajos porcentajes de mazorcas con mala cobertura y fueron los que mostraron los rendimientos promedio más altos. Estos genotipos son una alternativa para la producción de maíz en el área tropical del estado de Veracruz en virtud de las ventajas en cuanto a rendimiento y características agronómicas, por lo que se sugiere su validación agronómica.

\section{Calidad industrial y nutricional}

Los maíces de alta calidad de proteína (ACP) superaron la norma de calidad para la elaboración de tortillas. Son de grano pequeño, peso hectolítrito mayor de $74 \mathrm{~kg} / \mathrm{hl}$, índice de flotación menor de $40 \%$ (Cuadro 4), humedad de nixtamal superior al $42 \%$ establecido 
Cuadro 1. Rendimiento de grano (kg/ha) de genotipos de maíz en seis localidades del estado de Veracruz, México. 2006.

\begin{tabular}{|c|c|c|c|c|c|c|c|c|}
\hline Genotipo & $\begin{array}{l}\text { Ignacio de } \\
\text { la Llave }\end{array}$ & Tlalixcoyan & Cotaxtla & $\begin{array}{c}\text { Mata de } \\
\text { agua }\end{array}$ & $\begin{array}{c}\text { Martínez } \\
\text { de la Torre }\end{array}$ & $\begin{array}{l}\text { Rodríguez } \\
\text { Clara }\end{array}$ & Promedio & $\begin{array}{c}\% \\
\text { Rel }\end{array}$ \\
\hline HQ4 & $6,65^{* *}$ & $5,18 *$ & $7,74 *$ & $5,82 * *$ & $4,98 *$ & 2,15 & $5,42 *$ & 121 \\
\hline H-520 & $5,49 * *$ & $4,5^{*}$ & $7,33^{*}$ & $7,52 *$ & $4,15^{*}$ & $3,3 *$ & $5,38 *$ & 120 \\
\hline HQ3 & $5,8 * *$ & $5,2 *$ & $7,78^{*}$ & $5,71^{*}$ & $4,02 *$ & 2,26 & $5,13^{*}$ & 114 \\
\hline HQ1 & $5,73^{* *}$ & $4,98^{*}$ & $7,31^{*}$ & $5,2^{* *}$ & $3,82 * *$ & $3,3^{*}$ & $5,06^{*}$ & 113 \\
\hline H-518 & 4,12 & $5,53 *$ & $7,31 *$ & $6,29 * *$ & 3,26 & 2,05 & $4,76^{* *}$ & 106 \\
\hline HQ2 & $6,47 * *$ & $3,73 * *$ & $6,52 *$ & 4,9 & $3,59 * *$ & $3,11^{*}$ & 4,72 & 105 \\
\hline A-7573 & & $3,53 * *$ & $7,11^{*}$ & 4,5 & & $2,8^{*}$ & 4,49 & 100 \\
\hline VS-536 & $5,06 * *$ & $3,64 * *$ & $6,58 *$ & 4,58 & $4,15^{*}$ & 2,23 & 4,37 & 97 \\
\hline V-537C & 3,48 & 3,22 & $6,65^{*}$ & 4,1 & $3,96 * *$ & $3,52 *$ & 4,16 & 93 \\
\hline V-556AC & 4,13 & 2,83 & 5,89 & 2,9 & 3,29 & $2,73 *$ & 3,63 & 81 \\
\hline Promedio & 5,21 & 4,23 & 7,02 & 5,15 & 3,91 & 2,74 & 4,73 & \\
\hline $\mathrm{CV}(\%)$ & 13,97 & 16,38 & 8,55 & 13,73 & 10,85 & 15,05 & 12,68 & \\
\hline DMS0,05 & 1,68 & 1,57 & 1,36 & 1,62 & 1,01 & 0,93 & 0,49 & \\
\hline DMS0,01 & 2,44 & 2,25 & 1,95 & 2,32 & 1,46 & 1,34 & 0,66 & \\
\hline $\mathrm{CME}$ & 0,52 & 0,48 & 0,36 & 0,50 & 0,18 & 0,17 & 0,36 & \\
\hline
\end{tabular}

* = Significancia de los tratamientos al 0,05 de probabilidad.

** = Significancia de los tratamientos al 0,01 de probabilidad.

Cuadro 2. Rendimiento de grano promedio por localidad e índices ambientales. Parcelas de validación. Veracruz, México. 2006.

\begin{tabular}{lcc}
\hline Localidad y municipio & $\begin{array}{c}\text { Rendimiento } \\
\text { de grano } \\
(\mathbf{t} / \mathbf{h a})\end{array}$ & $\begin{array}{c}\text { Índices } \\
\text { ambien- } \\
\text { tales }\end{array}$ \\
\hline Cotaxtla, Medellín de Bravo, & $7,01^{*}$ & 2,28 \\
Mata de Agua, Adalberto Tejeda & 5,22 & 0,49 \\
Número Uno, Ignacio de la Llave & 5,21 & 0,48 \\
Remolino, Tlalixcoyan & 4,31 & $-0,42$ \\
Graciano Sánchez, Martínez de & & \\
la Torre & 3,91 & $-0,82$ \\
CBTA 85, Rodríguez Clara & 2,74 & $-1,99$ \\
\hline \multicolumn{1}{c}{$\quad$ Promedio } & $\mathbf{4 , 7 3}$ & \\
\hline
\end{tabular}

* Significancia para las localidades al 0,01 de probabilidad.

como máximo en la NMX-034 (2002), pérdidas de sólidos menores al $5 \%$ y rendimientos de tortillas frías en tres maíces, superiores al 1,5 kg por kg de maíz nixtamalizado. Con relación a la textura del grano, el HQ1 se ubicó como intermedio, mientras que HQ3, HQ4 y V-556AC fueron de textura dura.

Las tortillas fueron suaves y elásticas, de colores crema clara, brillante o amarilla en el caso de la V-556AC. Con el híbrido HQ1 se produjeron las mejores tortillas siguiendo el método tradicional de proceso de la masa y la elaboración de tortilla. Por su parte el HQ4 puede ser procesado exitosamente por la industria de la harina nixtamalizada, ya que desprende gran parte de su pericarpio después de la nixtamalización (Cuadro 5 y Figura 1). Destaca en los híbridos de grano blanco: el alto valor de reflectancia de sus harinas ( $\mathrm{x}=84,7 \%)$, la elevada absorción de agua de su nixtamal $(47,6 \%)$ y sus tortillas $(43,3 \%)$, lo que se reflejó en un mayor rendimiento de tortillas $(1,5 \mathrm{~kg} / \mathrm{kg}$ de maíz procesado).

Las tortillas del híbrido HQ-1, que fue el único de textura intermedia, proporcionó las tortillas más suaves (Figura 2) y con mayor elongación $\left(\mathrm{r}=0,77^{* *}\right)$. Finalmente, los nuevos híbridos de maíz de alta calidad 
Cuadro 3. Características agronómicas de diez genotipos de maíz en lotes de validación. Veracruz, México. 2006.

\begin{tabular}{ccccccccccc}
\hline Genotipo & $\begin{array}{c}\text { Altura } \\
\text { de la } \\
\text { planta }\end{array}$ & $\begin{array}{c}\text { Altura } \\
\text { de la } \\
\text { mazorca }\end{array}$ & $\begin{array}{c}\text { Días a } \\
\text { floración } \\
\text { masculina }\end{array}$ & $\begin{array}{c}\text { Días a } \\
\text { floración } \\
\text { femenina }\end{array}$ & $\begin{array}{c}\text { Aspec- } \\
\text { to de la } \\
\text { planta }\end{array}$ & $\begin{array}{c}\text { Sanidad } \\
\text { de la } \\
\text { planta }\end{array}$ & $\begin{array}{c}\text { Porcentaje } \\
\text { de mazorcas } \\
\text { podridas }\end{array}$ & $\begin{array}{c}\text { Aspecto } \\
\text { de la } \\
\text { mazorca }\end{array}$ & $\begin{array}{c}\text { Sanidad } \\
\text { de la } \\
\text { mazorca }\end{array}$ & $\begin{array}{c}\text { Porcentaje de } \\
\text { mazorcas con } \\
\text { mala cobertura }\end{array}$ \\
\hline HQ1 & 242 & 112 & 56 & 57 & 1,71 & 1,54 & 4,18 & 1,9 & 2,05 & 0,47 \\
HQ2 & 222 & 101 & 56 & 57 & 2,58 & 2,42 & 3,63 & 2,35 & 2,4 & 6,40 \\
HQ3 & 227 & 109 & 57 & 58 & 2,13 & 2,08 & 5,85 & 2,15 & 2,2 & 2,70 \\
HQ4 & 229 & 110 & 57 & 58 & 1,88 & 1,96 & 4,18 & 1,5 & 1,5 & 2,80 \\
H-518 & 223 & 104 & 56 & 57 & 1,96 & 2,04 & 4,96 & 2,35 & 2,4 & 9,77 \\
H-520 & 233 & 111 & 56 & 56 & 1,75 & 1,88 & 5,72 & 1,8 & 1,9 & 2,61 \\
VS-536 & 234 & 118 & 55 & 56 & 2,46 & 2,58 & 6,38 & 2,35 & 2,45 & 6,80 \\
V-537C & 241 & 117 & 53 & 54 & 2,54 & 2,63 & 5,17 & 2,7 & 2,75 & 5,86 \\
V-556AC & 234 & 117 & 52 & 53 & 2,92 & 2,88 & 8,03 & 2,65 & 2,8 & 8,50 \\
A-7573 & $\mathbf{2 2 9}$ & 107 & 53 & 53 & 2,81 & 2,62 & 7,33 & 3,33 & 3,42 & 10,63 \\
\hline Promedio & $\mathbf{2 3 0 , 2}$ & $\mathbf{1 1 0 , 4}$ & $\mathbf{5 5 , 4}$ & $\mathbf{5 6 , 3}$ & $\mathbf{2 , 2 2}$ & $\mathbf{2 , 2 1}$ & $\mathbf{5 , 5 4}$ & $\mathbf{2 , 2 8}$ & $\mathbf{2 , 2 8}$ & $\mathbf{5 , 6 5}$ \\
\hline
\end{tabular}

Cuadro 4. Características físicas del grano en maíces de calidad proteínica (ACP). Cotaxtla, Veracruz, México. 2006.

\begin{tabular}{|c|c|c|c|c|c|c|c|c|}
\hline & \multirow{2}{*}{$\begin{array}{l}\text { Peso cien } \\
\text { granos }(\mathrm{g})\end{array}$} & \multirow{2}{*}{$\begin{array}{l}\text { Peso hectoli- } \\
\text { trico }(\mathrm{kg} / \mathrm{hl})\end{array}$} & \multirow{2}{*}{$\begin{array}{c}\text { Índice de flo- } \\
\text { tación }(\%)\end{array}$} & \multirow[t]{2}{*}{ Textura } & \multicolumn{2}{|c|}{ Reflectancia } & \multicolumn{2}{|c|}{ Color Hue* } \\
\hline & & & & & Grano entero & Harina & Grano entero & Harina \\
\hline HQ-1 & $26,97 * *$ & 75,4 & 39 & Intermedia & $55^{* *}$ & 81 & $83,5 * *$ & $89,9 * *$ \\
\hline HQ-3 & $27,38 * *$ & 79,1 & 26 & Dura & $56 * *$ & 88 & $82,8 * *$ & $90,1 * *$ \\
\hline HQ-4 & $27,20 * *$ & 79,5 & 23 & Dura & $54 * *$ & 85 & $82,5 * *$ & 89,7 \\
\hline V-556AC & 24,90 & $82,5^{* *}$ & $17 * *$ & Dura & 38 & 78 & 65,5 & 80,3 \\
\hline DMS*** & 2,45 & 1,12 & 7 & & 2 & & 1,1 & 0,24 \\
\hline NMX/034(2002) **** & & $>74$ & $<40$ & & $>55$ & $>77$ & & \\
\hline
\end{tabular}

* Tono de la coloración en el colorímetro Hunter Lab modelo 45/0-L.

** Significancia de los tratamientos al 0,05 de probabilidad.

***DMS= Diferencia Mínima Significativa.

**** Valores establecidos por La Norma Mexicana para Maíz Nixtamalizado.

Cuadro 5. Variables de la calidad de nixtamal y de las tortillas en híbridos de maíz de alta calidad de proteína (ACP). Cotaxtla, Veracruz, México. 2006.

\begin{tabular}{llllccccc}
\hline & \multicolumn{2}{c}{ Humedad (\%) } & Sólidos & Rendimiento & Fuerza (gramo fuerza) & \multicolumn{2}{c}{ Color Hue* } \\
\cline { 2 - 8 } & Nixtamal & Tortillas & $\mathbf{( \% )}$ & Tortilla fría & $\mathbf{2 ~ h}$ & $\mathbf{2 4} \mathbf{h}$ & $\mathbf{2 ~ h}$ & $\mathbf{2 4} \mathbf{~ h}$ \\
\hline HQ-1 & 46,9 & $43,9^{* *}$ & $3,6^{* *}$ & 1,51 & $465,3^{* *}$ & 480,1 & 90,6 & $91,7^{* *}$ \\
HQ-3 & $48,8^{* *}$ & $42,5^{* *}$ & 3,2 & 1,43 & $483,7^{* *}$ & 537,2 & 91,4 & $91,5^{* *}$ \\
HQ-4 & 47,0 & $43,4^{* *}$ & 3,0 & $1,55^{* *}$ & $470,5^{* *}$ & $717,7^{* *}$ & 91,3 & $91,4^{* *}$ \\
V-556AC & 45,1 & 40,2 & 2,9 & 1,51 & 427,3 & 567,1 & 80,2 & 80,9 \\
DMS*** & 1,47 & 2,8 & 0,2 & 0,03 & 25,1 & 81,8 & & 0,9 \\
NMX034(2002) & $36-42$ & & $<5,0$ & & & & & \\
\hline
\end{tabular}

* Tono de la coloración en el colorímetro Hunter Lab modelo 45/0-L.

** = Significancia de los tratamientos al 0,05 de probabilidad.

*** DMS= Diferencia Mínima Significativa. 

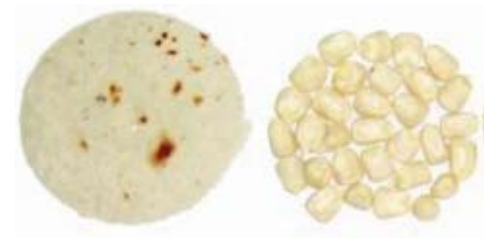

\#12D HQ-4
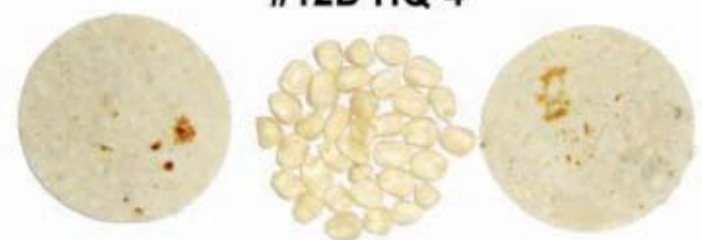

\#16D HQ-1
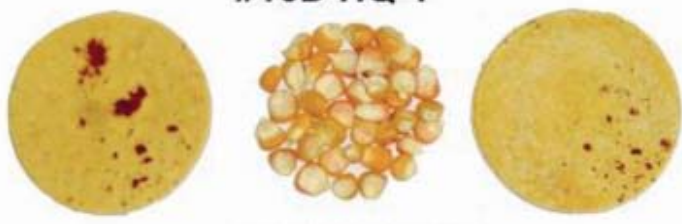

\#18D V-556AC
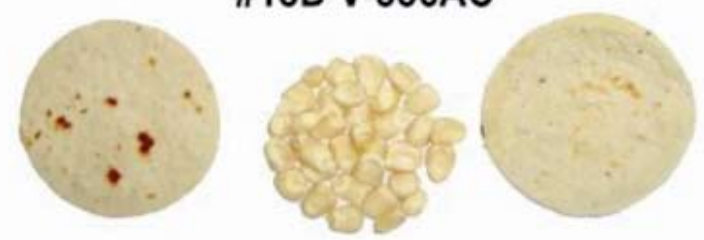

\section{\#19D HQ-3}

Figura 1. Aspecto del grano y tortillas de maíces de alta calidad de proteína (ACP). Cotaxtla, Veracruz, México. 2006.

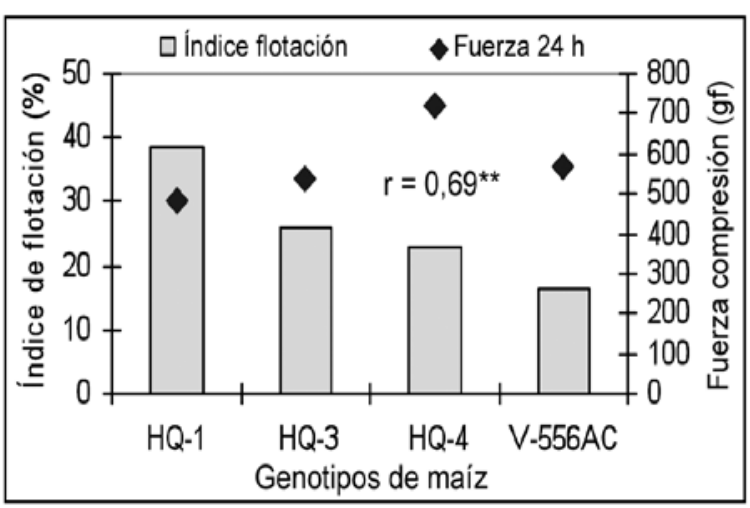

Figura 2. Correlación entre la dureza del grano y la de las tortillas, de maíces de alta calidad de proteína (ACP). Cotaxtla, Veracruz, México. 2007.

proteínica son una alternativa viable para incrementar los rendimientos, mejorar la nutrición y elaborar tortillas con buena calidad.

Desde el punto de vista nutricional los maíces ACP tuvieron más lisina y triptofano en su endospermo que el testigo normal (Cuadro 6), y muy próximos a los valores informados en la literatura para los maíces ACP. Destaca el híbrido HQ-3 por el mayor contendido en su endospermo de estos aminoácidos, además, fue el de mayor contenido de triptofano en grano entero, y durante la transformación a tortilla se perdió el $27 \%$, de este aminoácido, valor que fue ligeramente superior al 15\% (Ortega et al. (1986).

Cuadro 6. Contenidos de aceite, lisina y triptofano en endospermo, grano entero y tortillas de maíces de alta calidad de proteína. Cotaxtla, Veracruz, México. 2006.

\begin{tabular}{lcccccc}
\hline & Aceite & \multicolumn{2}{c}{ Lisina (\%) } & \multicolumn{3}{c}{ Triptofano (\%) } \\
\cline { 3 - 7 } Genotipo & $(\boldsymbol{\%})$ & Endospermo & Grano entero & Endospermo & Grano entero & Tortillas \\
\hline HQ-1 & $4,41^{*}$ & 0,230 & 0,310 & $0,071^{*}$ & 0,075 & 0,068 \\
HQ-3 & 4,28 & $0,262^{*}$ & 0,294 & $0,076^{*}$ & $0,104^{*}$ & 0,076 \\
HQ-4 & 4,23 & 0,233 & $0,352^{*}$ & 0,066 & 0,086 & 0,058 \\
V-556AC & 4,23 & 0,248 & 0,334 & 0,066 & 0,081 & $0,081^{*}$ \\
\hline DMS & 0,12 & 0,006 & 0,008 & 0,0057 & 0,0126 & 0,0059 \\
Maíz de alta calidad de proteína & 0,289 & 0,414 & 0,072 & 0,0989 & 0,903 \\
Maíz normal & & 0,210 & 0,252 & 0,045 & 0,055 & 0,05 \\
\hline
\end{tabular}

*=Significancia de los tratamientos al 0,05 de probabilidad.

DMS= Diferencia Mínima Significativa. 


\section{LITERATURA CITADA}

American Association of Cereal Chemists (AACC). 1998. Approved methods of the American Association of Cereal Chemists. 10 ed. The Association: St. Paul, MN. USA. 1200 p.

Antuna, O; Rodríguez, S; Arámbula, G; Palomo, A; Gutiérrez, E; Espinoza, A; Navarro, E; Andrio, E. 2008. Calidad nixtamalera y tortillera en maíces criollos de México. Revista Fitotecnia Mexicana 31(3):23-27.

Arámbula, G; Mauricio, R; Figueroa, JD; González, J; Ordorica, FC. 2001. Physico chemical structural and textural properties of tortillas from extrused instant corn fluor supplemented with various types of corn lipids. J. Cereal Sci. 33:245-252.

Association of Official Analytical Chemists. 1984. Official Methods of Analysis the Association of Official Analytical Chemists. 13 ed. p. 132-133.

Bressani, R. 1994. Opaque 2 corn in human nutrition and utilization. In: Quality protein maize. 1964-1994. Proc. of the international symposium on quality protein maize. EMBRAPA/CNPMS, Sete Lagoas MG Brasil. p. 41-63.

Chávez, A; Chávez, M de. 2004. La tortilla de alto valor nutritivo. Mc Graw Hill. México, D.F. 110 p.

Coutiño, B; Vásquez, G; Torres, B; Salinas, Y. 2008. Calidad de grano tortillas y botanas de dos variedades de maíz de la raza comiteco. Revista Fitotecnia Mexicana 31(3):9-14.

Espinosa, A; Gómez, N; Sierra, M; Betanzos, E; Caballero, F. 2006. Variedades e híbridos de calidad proteínica. Academia Mexicana de las Ciencias. Revista Ciencia. 57(3):28-34.

García, E. 1981. Modificaciones al sistema de clasificación climática de Köppen. 3 ed. Universidad Nacional Autónoma de México. Instituto de Geografía. México D.F., México. 252 p.

Larkins, A; Dannehoffer, F; Bostwick, O; Moro, A; Lopez, MA. 1994. Opaque 2 modifiers, what they are and how they work. In: Quality protein maize. 1964-1994. Proc. of the international symposium on quality protein maize. EMBRAPA/CNPMS, Sete Lagoas MG Brasil. p. 133-148.

McGuire, G. 1992. Reporting objective color measurements. Hort. Sci. (27):1254-1255.

Mertz, T. 1994. Thirty years of opaque 2 maize. In: Quality Protein Maize. 1964-1994. Proc. of Symp. of Quality Protein Maize. EMBRAPA/CNPMS, Sete Lagoas M. G. Brasil. p. 1-10.
Morris, L; López, MA. 2000. Impactos del mejoramiento de maíz en América Latina 1966-1997. México D.F. CIMMYT 45 p.

Norma Mexicana para Maíces Destinados al Proceso de Nixtamalización, NMX-FF-034-2002-SCFI-PARTE 1 (2002). Productos alimenticios no industrializados para consumo humano-cereales-maíz blanco para proceso alcalino para tortillas de maíz y productos de maíz nixtamalizado. Especificaciones y métodos de prueba. Secretaría de Agricultura, Ganadería, Desarrollo Rural, Pesca y Alimentación (SAGARPA), Dirección General de Normas. México D.F. 18 p.

Ortega, E; Villegas, E; Vasal, SK. 1986. A comparative study of protein changes in normal and quality protein maize during tortilla making. Cereal Chemistry 63: 446-451.

Ortega, A; Cota, O; Vasal, SK; Villegas, E; Córdova, H; Barrera, MA; Wong, JJ; Reyes, CA; Preciado, RE; Terrón, A; Espinosa, A. 2001. H-441C, H-442C y H469C, híbridos de maíz de calidad proteínica mejorada para el Noroeste y Subtrópico de México. Folleto Técnico Núm. 41. SAGARPA. INIFAP. CIRNO. CEVY. Obregón Son. México. 44 p.

Reyes, P. 1990. Diseño de experimentos aplicados. Ed. Trillas 3 ed. 348 p.

SAGARPA (Secretaría de Agricultura, Ganadería, Desarrollo Rural, Pesca y Alimentación). 2002. Servicio de información y estadística agroalimentaria y pesquera. Subsistema de información agrícola. SAGARPA México D.F. s/p.

SAGARPA (Servicio de Información y Estadística Agroalimentaria y Pesquera-Secretaría de Agricultura, Ganadería, Desarrollo Rural, Pesca y Alimentación). 2008. Servicio de Información y Estadística Agroalimentaria y Pesquera. Anuario estadístico de la producción agrícola de los Estados Unidos Mexicanos. (en línea). Consultado 11 set. 2008. Disponible en http//www. siap.sagarpa.gob.mx

Salinas, MY; Vázquez, MG. 2006. Metodologías de análisis de calidad nixtamalera-tortillera en maíz. Folleto técnico No. 22. INIFAP. Campo Experimental Valle de México. Chapingo, Edo. de México. México. 80 p.

Sierra, M; Palafox, A; Becerra, EN; Córdova, H; Espinosa, A; Rodríguez, FA. 2007. Comportamiento de híbridos de maíz con alta calidad de proteína, por su rendimiento y tolerancia al "Achaparramiento". Agronomía Mesoamericana 18(1):27-35.

Sierra, M; Palafox, A; Cano, O; Rodríguez, FA; Espinosa, A; Turrent, A; Gómez, N; Córdova, H; Vergara, N; 
Aveldaño, R; Barrón, S; Romero, J; Caballero, F; González, M; Betanzos, E. 2001. Descripción varietal de H-519C, H-553C y V-537C, maíces con alta calidad de proteína para el trópico húmedo de México. INIFAP CIRGOC. Campo Experimental Cotaxtla. Folleto Técnico Núm.30. Veracruz, Veracruz, México. $21 \mathrm{p}$.

Sierra, M; Palafox, A; Rodríguez, FA; Espinosa, A; Gómez, N; Caballero, F; Barrón, S; Zambada, A. 2004a. H-518 y H-520, híbridos trilineales de maíz para el trópico húmedo de México. INIFAP. CIRGOC.
Campo Experimental Cotaxtla. Folleto Técnico Núm. 38. Veracruz, México. 17 p.

Vasal, SK; Vergara, N; Mc Lean, S. 1994. Estrategias en el desarrollo de híbridos tropicales de maíz. Agronomía Mesoamericana 5:184-189.

Vasal, SK; Villegas, E. 2001. The quality protein maize revolution. Improved nutrition and livelihoods for the poor. CIMMYT, El Batán Texcoco, Mex. 7 p.

Vasal, SK. 2002. High quality protein corn. In: Hallauer, AR. ed. Specialty corns. 2 ed. CRC Press, Boca Raton, Fl. USA. p. 85-129. 